\title{
Adaptasi dan Validasi Alat Ukur Perilaku Inovatif Karyawan
}

\author{
Iffah Rosyiana, Fendy Suhariadi, Seger Handoyo, Fajrianthi \\ Program Studi Doktoral Psikologi Universitas Airlangga Surabaya, Indonesia \\ e-mail: iffah.rosyiana-13@psikologi.unair.ac.id
}

\begin{abstract}
The growth of the hotel business is increasing, along with the development of tourism. This condition encourages hoteliers to compete to advance their business with a variety of service innovation processes. Therefore, it is essential to know and identify the innovative behavior of hospitality employees. This study aims to develop innovative employee behavior measurement tools. We used a quantitative study involving 143 sales marketing employees in hospitality as respondents. The sample selection uses a random sampling technique. The development of innovative behavioral questionnaires was revealed through three dimensions, namely the idea generation dimension, idea championing, and idea implementation. Data analysis used confirmatory factor analysis (CFA) with the help of Amos 22 software. The results of the study revealed that the innovative behavior measurement model met the goodness of fit criteria. These findings indicate that innovative behavior can be measured by the dimensions of idea generation, idea championing, and idea implementation. The results of this study also have implications for several hospitality practitioners to evaluate the innovative behavior of hospitality employees.
\end{abstract}

Keywords: innovative behavior, scale adaptation, validity, confirmatory factor analysis

\begin{abstract}
Abstrak
Pertumbuhan bisnis perhotelan semakin pesat seiring perkembangan pariwisata. Kondisi ini mendorong pelaku bisnis perhotelan bersaing untuk memajukan bisnisnya dengan berbagai proses inovasi layanan jasanya. Oleh karena itu, sangat penting untuk mengetahui dan mengidentifikasi perilaku inovatif karyawan perhotelan. Studi ini bertujuan untuk mengembangkan alat ukur perilaku inovatif karyawan perhotelan. Studi ini merupakan penelitian kuantitatif dengan melibatkan 143 karyawan sales marketing di perhotelan sebagai responden. Pemilihan sampel menggunakan teknik random sampling. Pengembangan kuesioner perilaku inovatif diungkap melalui tiga dimensi yaitu dimensi idea generation, idea championing, dan idea implementation. Analisis data menggunakan confirmatory factor analysis (CFA) dengan bantuan software Amos 22. Hasil studi mengungkapkan bahwa model pengukuran perilaku inovatif telah memenuhi kriteria goodness of fit. Temuan ini mengindikasikan bahwa perilaku inovatif dapat diukur dengan dimensi idea generation, idea championing, dan idea implementation. Hasil studi ini juga memberikan implikasi pada sejumlah praktisi perhotelan untuk mengevaluasi perilaku inovatif karyawan perhotelan.
\end{abstract}

Kata Kunci: perilaku inovatif, adaptasi skala, validitas, confirmatory factor analysis

\section{Pendahuluan}

Globalisasi dan digitalisasi telah mendorong industri untuk mengubah berbagai jenis layanan sebagai akibat tuntutan industri 4.0 (Christoph dkk., 2018; Kagermann, 2015). Upaya agar industri mampu bersaing untuk lebih inovatif yaitu dengan cara mendorong kemampuan karyawan mereka untuk berinovasi. Industri perlu terlibat dalam proses peningkatan dan inovasi berkelanjutan di tempat kerja dengan menggunakan kemampuan dinamis mereka untuk mempertahankan keunggulan kompetitif mereka (Metcalfe \& Miles, 2012). Para karyawan perlu memiliki kemampuan dinamis untuk berinovasi dan mendorong inovasi berkelanjutan (Caloghirou dkk., 2004; De Jong \& Den Hartog, 2007; Mahfud dkk., 2017; Mahfud dkk., 2019). Sehingga tidak 
mengherankan, dalam beberapa tahun terakhir, inovasi berkelanjutan melalui perilaku inovatif telah banyak mendapat perhatian yang meningkat dari para peneliti (Martin dkk., 2018; Rigtering dkk., 2019) dan praktisi (Deeb, 2015).

Basis pekerjaan di masa depan akan berubah menjadi berbasis pengetahuan dan menuntut tidak terlalu kaku. Dalam konteks ini, tenaga kerja memiliki peran untuk meningkatkan kinerja individu maupun kinerja perusahaan dengan melakukan berbagai inovasi produk maupun layanan agar lebih baik dari sebelumnya. Banyak para ahli telah mengkaji tentang peran perilaku inovasi terhadap peningkatan kinerja dan kesuksesan organisasi (Akram dkk., 2020; Kör dkk., 2020; Wu dkk., 2020; Wu dkk., 2018). Untuk mewujudkan proses inovasi yang berkelanjutan, karyawan harus mau dan mampu berinovasi.

Dalam konteks Indonesia, hadirnya Masyarakat Ekonomi Asia (MEA) pada tahun 2015 telah mendorong Indonesia untuk terlibat dalam mempersiapkan calon tenaga kerja yang inovatif untuk mampu bersaing di masa depan. MEA tidak hanya membawa peluang, namun juga sekaligus membawa tantangan bagi setiap negara untuk berkompetisi secara terbuka. Setiap negara harus mampu menyiapkan SDM yang kompetitif dan inovatif, maka negara tersebut akan mampu menghadapi persaingan global dan mencapai kemajuan. sementara itu, negara yang tidak dapat memanfaatkan peluang ini dengan baik, maka negara tersebut akan menghadapi sejumlah permasalahan dan ketertinggalan.

Peningkatan kualitas SDM agar berperilaku inovatif sangatlah penting. Perilaku inovatif diyakini mampu mendorong dan meningkatkan produktivitas kerja dan pada akhirnya akan memberikan dampak pada peningkatan perolehan profit usaha. Produktivitas merupakan perilaku yang mendorong terhadap peningkatan kinerja pribadi maupun lembaga (Suhariadi, 2002). Perilaku kerja inilah yang dikatakan sebagai perilaku produktif pada tenaga kerja yang di dalamnya terdiri dari komponen perilaku efektif dan perilaku efisien. Perilaku efektif dan efisien dibentuk melalui proses yang panjang, pada perilaku efektif atau perilaku individu yang mengarah pada pencapaian tujuan ternyata membutuhkan kedisiplinan dan daya tahan yang tinggi terhadap kegagalan yang dialaminya. Hal tersebut terjadi pada pekerjaan yang menuntut keberagaman keterampilan dan evaluasi umpan balik atas hasil pencapaiannya. Perilaku efisien merupakan perilaku yang berorientasi pada usaha individu memanfaatkan secara maksimal dan hemat terhadap sumber daya yang ada, sarana, prasarana dan dana yang tersedia. Perilaku efisien ini terbentuk dari perasaan puas individu yang memiliki keterlibatan keanggotaan dengan organisasi.

Selain itu, pemetaan perilaku produktif dan inovatif diperoleh dari fungsi karakteristik individu dan lingkungan yang memberikan dampak terhadap kinerja karyawan dan organisasi yang positif agar dapat meraih sasaran perusahaan (Rosyiana, 2019). Sehingga dapat disimpulkan bahwa produktivitas dalam suatu organisasi tidak hanya mengacu pada hitungan teknis saja namun dapat pula bersumber dari perilaku inovatif individu sebagai anggota organisasi yang melibatkan sisi psikologis dan lingkungannya.

Kondisi tersebut mendorong setiap negara untuk mereformasi program pendidikan dan pelatihan kerja yang mengarah pada peningkatan perilaku inovatif yang mengarah pada peningkatan produktivitas. Peningkatan kualitas SDM tidak saja menjadi tanggung jawab pemerintah, namun semua stakeholder juga turut bertanggung jawab untuk terlibat dalam pengembangan SDM. Kebutuhan tenaga kerja yang terampil saja tidaklah cukup dapat memenangkan persaingan tenaga kerja, diperlukan sikap dan perilaku kerja produktif yang didukung dengan kreativitas dan perilaku inovatif dari kondisi sebelumnya. Oleh karenanya, 
sangat penting bagi organisasi dalam rangka memenangkan kompetisi persaingan bisnis salah satunya adalah mengetahui perilaku inovatif pada karyawan, sehingga dapat diidentifikasi dan disusun program pengembangan karyawan agar dapat meningkatkan perilaku inovatif.

Perilaku inovatif bagi tenaga kerja menjadi aspek penting dalam menghadapi persaingan kerja di masa depan (Mahfud dkk., 2017, 2019). Selain itu, persaingan bisnis perhotelan sangat memerlukan perilaku inovatif tenaga kerjanya untuk meningkatkan kunjungan tamu. Tamu akan tertarik dengan inovasi baru yang ditawarkan oleh bisnis perhotelan. Dengan demikian, perilaku inovatif bagi karyawan hotel akan mendorong peningkatan kunjungan tamu hotel.

Potensi persaingan di industri perhotelan terlihat dari data kunjungan tamu. Secara empirik, pada tahun 2016 kunjungan tamu perhotelan mengalami peningkatan dari tahun sebelumnya sebesar 9.54\%. Selain itu, data BPS (Badan Pusat Statistik) juga menunjukkan peningkatan kunjungan tamu perhotelan setiap tahunnya (Bapan Pusat Statistik, 2015). Kondisi ini memberikan peluang bagi pihak hotel untuk menarik tamu sebanyak-banyaknya agar dapat menginap di hotelnya. Disamping itu, kondisi ini juga menyiratkan tentang semakin ketatnya persaingan industri perhotelan. Oleh karena itu, setiap industri perhotelan akan memerlukan tenaga kerja yang kreatif, inovatif dan memiliki keterampilan yang memenuhi kompetensi kerja di bidangnya untuk meningkatkan kunjungan tamu di hotelnya.

Hasil penelitian dari Tewal (2010) menyatakan bahwa inovasi yang dilakukan perusahaan perhotelan berpengaruh signifikan terhadap kinerja perhotelan. Studi sebelumnya juga mengungkapkan bahwa SDM industri perhotelan harus kreatif dan inovatif (Mahfud dkk., 2017, 2019; Wu dkk., 2018). Selanjutnya, Anshori (2010) dalam studinya menunjukkan bahwa orientasi pasar, orientasi pembelajaran manajer, dan intellectual capital memiliki pengaruh yang signifikan terhadap inovasi dan kinerja hotel bintang empat dan lima di Jawa Timur. Pada penelitian Yong dan Elsye (2016) menunjukkan bahwa marketing capability memiliki korelasi dengan innovation capability. Selain itu, innovation capability juga menunjukkan adanya hubungan dengan financial performance. Terakhir, marketing capability memiliki hubungan dengan financial performance.

Hasil dari berbagai penelitian sebelumnya mengungkapkan bahwa terdapat hubungan yang cukup signifikan antara perilaku inovatif dengan kinerja dan performance perhotelan. Meskipun telah banyak studi sebelumnya yang menyoroti pentingnya perilaku inovatif bagi karyawan perhotelan, namun masih terbatas studi yang menguji alat ukur perilaku inovatif pada karyawan perhotelan. Misalnya, beberapa studi sebelumnya belum mengungkap validasi (Basu \& Green, 1997; Bunce \& West, 1995; Jung \& Yoon, 2018; Kwon \& Kim, 2020; Luu, 2019; Zhou \& George, 2001). Studi-studi tersebut belum mengulas validasi perilaku inovatif.

Studi lainnya menyatakan bahwa perilaku inovatif mencakup kreativitas dan pengambilan risiko (Byrd \& Brown, 2003). Selain itu, perilaku inovatif terdiri dari idea generation, idea championing, dan idea implementation (De Jong \& Den Hartog, 2007; De Jong \& Hartog, 2008). Dimensi idea generation menjelaskan tentang seputar eksplorasi pemecahan masalah yang dihadapi. Eksplorasi tersebut dapat dilakukan dengan cara mengomunikasikan dengan orang lain. Idea championing merupakan usaha seseorang menyampaikan idenya kepada orang lain. Sementara itu, idea implementation merupakan proses pengujian ide atau gagasan yang ditemukan. Proses ini akan berakhir pada penciptaan suatu produk baru sebagai solusi atas permasalahan yang dihadapi. 
Berdasarkan penjelasan dari berbagai studi sebelumnya dan keterbatasan studi yang membahas tentang validasi perilaku inovatif, maka diperlukan studi untuk menguji alat ukur perilaku inovatif bagi karyawan perhotelan. Dengan demikian, studi ini bertujuan untuk menguji alat ukur perilaku inovatif karyawan perhotelan dengan melibatkan dimensi idea generation, idea championing, dan idea implementation.

\section{Metode Penelitian}

Penelitian ini merupakan penelitian kuantitatif dengan jenis ex-post facto. Studi ini melibatkan karyawan di bagian sales marketing perhotelan dengan jumlah populasi sebanyak 230 karyawan. Mengacu pada ukuran sampel oleh Krejcie dan Morgan (1970) didapatkan ukuran sampel sejumlah 143. Teknik sampling yang digunakan yaitu simple random sampling. Pengumpulan data mengunakan kuesioner online.Jumlah karyawan yang mengisi secara lengkap berjumlah 143 karyawan di bagian sales marketing perhotelan (lihat tabel 1) yang berasal dari berbagai daerah dan kota besar yaitu: Bandung, Jakarta, Yogyakarta dan Bali.

Tabel 1

Data Demografis Subjek

\begin{tabular}{lc}
\hline \multicolumn{1}{c}{ Kategori } & $(\mathrm{N}=143)$ \\
\hline Gender & \\
Laki-laki & 83 \\
Perempuan & 60 \\
Usia & \\
$<25$ tahun & 62 \\
$25-35$ tahun & 62 \\
$36-50$ tahun & 17 \\
50 tahun ke atas & 2 \\
Lama Bekerja & \\
$<3$ tahun & 54 \\
3-5 tahun & 51 \\
6-10 tahun & 29 \\
$>10$ tahun & 9 \\
Pendidikan & \\
Di bawah SMA & 0 \\
SMA/SMK & 39 \\
Diploma & 58 \\
S1/S2/S3 & 46 \\
\hline
\end{tabular}

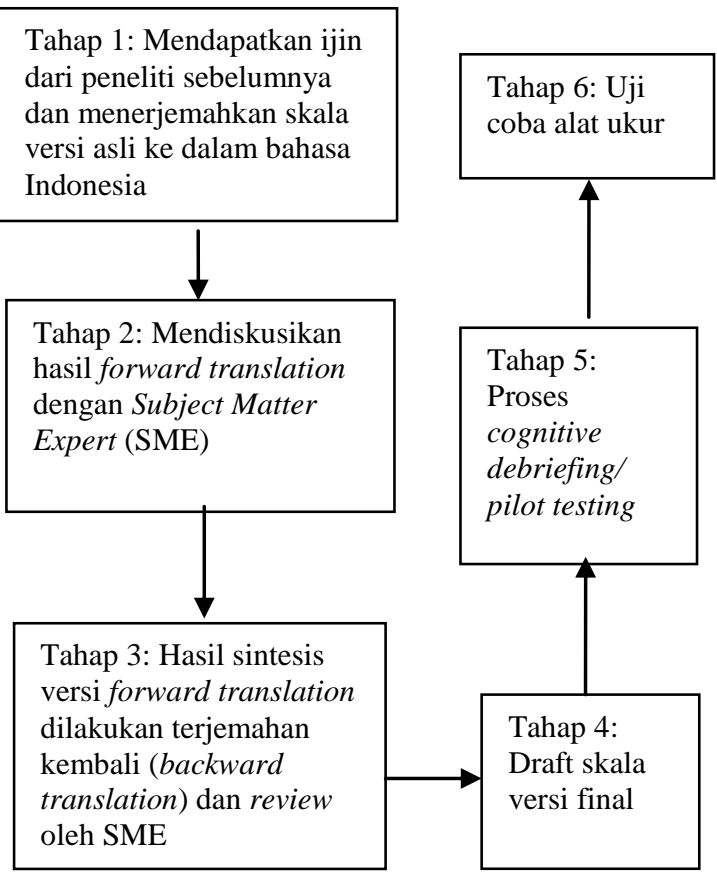

Gambar 1. Skema adaptasi alat ukur

Penelitian ini menggunakan adaptasi dari penelitian sebelumnya. Meskipun mengadaptasi dari penelitian sebelumnya, namun tetap menggunakan acuan dari International Test Committee (ITC) guidelines for translating and adapting test. Tahapan adaptasi ditunjukkan pada gambar 1. Pada tahap 1 peneliti menghubungi peneliti sebelumnya (De Jong \& Hartog, 2008) untuk mendapatkan izin penggunaan kuesioner. Selanjutnya, pada tahap 2 melakukan proses translasi ke dalam bahasa Indonesia (forward translation). Pada tahap ini melibatkan ahli bahasa untuk diterjemahkan ke dalam bahasa Indonesia (forward translation). Pada tahap 3, dilakukan proses translasi kembali ke dalam bahasa Inggris (backward translation).

Selanjutnya, pada tahap 4 dilakukan review forward translation dan backward translation. Proses review ini melibatkan para ahli yaitu ahli di bidang bahasa, Psikologi Industri dan Organisasi serta praktisi perhotelan. Ketiga bidang ahli tersebut diberikan form kesediaan untuk menjadi experts review dan diberikan uraian mengenai definisi operasional setiap 
variabel, uraian singkat tentang penelitian dan metodologinya. Setiap ahli diberikan form penilaian mengenai perbandingan bahasa (comparability) dan kesamaan makna (similaritiy) antara skala versi orisinal dengan versi back translate.

Hasil penilaian tingkat comparability dan similarity item dari lima ahli, selanjutnya dihitung mean score dari setiap item. Menurut Spearber (2004), item yang ekuivalen adalah item-item dengan mean score < 4. Pada penelitian ini memakai skal 1-5, dengan mean score $>3$ adalah memiliki comparability maupun similarity yang baik sehingga dapat diperbandingkan dan memiliki makna yang sama dengan versi asli. Pada tahap 5 dilakukan pilot testing. Pada tahap ini skala perilaku inovatif telah siap uji dan dilakukan pilot testing dengan mengundang tujuh orang praktisi sales marketing perhotelan untuk mengisi dan memberikan feedback kuesioner perilaku inovatif. Pada tahap akhir, peneliti melakukan uji coba alat ukur. Pada tahap ini skala perilaku inovatif sudah siap diberikan kepada karyawan sales marketing. Proses ini dilakukan untuk menguji validitas alat ukur berdasarkan evidence based on test content dan evidence based on internal structure.

Validitas dalam penelitian ini disebut sebagai validitas konstruk yaitu tipe validitas yang bertujuan untuk menguji konstruk teoretis dengan data lapangan. Validitas ini memerlukan teknik analisa statistik (Azwar, 2010). Studi ini menggunakan confirmatory factor analysis (CFA) untuk menguji validitas konstruk perilaku inovatif.

Selain itu, studi ini menggunakan bantuan software Amos 22. Analisis CFA digunakan untuk menguji apakah indikator-indikator tersebut merupakan indikator yang valid sebagai pengukur konstruk laten (Azwar, 2010). Analisis CFA digunakan untuk melihat kecocokan model (fit model) pengukuran perilaku inovatif. Adapun kriteria penentuan fit model ditunjukkan pada tabel 2.
Tabel 2

Goodness of Fit Standart

\begin{tabular}{lc}
\hline \multicolumn{1}{c}{$\begin{array}{c}\text { Goodness of Fit } \\
\text { Measures }\end{array}$} & Cut Off Value \\
\hline Absolute fit Indices & \\
Chi Squares & $<106.395$ \\
GFI & $\geq .8$ \\
RMR & $\leq .08$ \\
RMSEA & $<.08$ \\
Incremental fit Indices & $\geq .8$ \\
AGFI & $\geq .8$ \\
NFI & $\geq .8$ \\
CFI & $\geq .8$ \\
IFI & $.60-.90$ \\
Parsintony fit Indices & $.50-1.00$ \\
PNFI & \\
PGFI &
\end{tabular}

Sumber: (Hair dkk., 2010)

\section{Hasil Penelitian dan Pembahasan}

Pengujian alat ukur perilaku inovatif dimulai dari uji validitas isi alat ukur. Uji validitas isi ini melibatkan para ahli (expert judgment) sejumlah 5 orang. Validitas ini memiliki tujuan untuk menyeleksi itemitem yang baik dan tidak baik. Bila dinilai oleh lima ahli atau lebih sedikit, nilai I-CVI harus 1.00. Apabila ada enam atau lebih ahli, standarnya bisa lebih longgar, tetapi ICVI tidak lebih rendah dari .78 (Polit \& Beck, 2006). Adapun item-item yang memiliki I-CVI yang sangat rendah sebaiknya dihapus. Pada penelitian ini menurut Azwar (2010) untuk item-item pada skala terdapat 8 skala yang diuji menggunakan CVI dengan rumus sebagai berikut:

$$
\mathbf{V}=\sum \mathbf{s} /(\mathbf{n} * \mathbf{( c - 1 )})
$$

$\mathrm{V}=$ Koefisien validitas isi Aiken's Item

$\mathrm{S}=$ Hasil pengurangan angka penilaian panelis dengan angka penilaian validitas terendah (rlo)

$\mathrm{n}=$ Jumlah panelis

$\mathrm{r}$ = Angka yang diberikan oleh panelis

c = Angka penilaian validitas yang tertinggi (3)

lo = Angka penilaian validitas yang Terendah (1)

Pada rumus tersebut telah dilakukan perhitungan. Adapun hasil perhitungan pada skala perilaku inovatif ditunjukkan pada tabel 3. Tabel 3 menunjukkan bahwa keseluruhan item memiliki nilai I-CVI 1.00 
pada semua aspek penilaian yang meliputi clarity, relevancy, dan importancy. Pada tahap validasi ini dimensi idea generation dapat diukur dengan 3 item, dimensi idea championing terdiri dari 4 item dan dimensi idea implementation terdiri dari 3 item. Dengan demikian dapat dikatakan bahwa tidak ada item yang tereliminasi pada uji validitas isi ini. Selanjutnya, keseluruhan butir yang tervalidasi dilakukan uji validitas konstruk dengan menggunakan analisis confirmatory factor analysis (CFA). CFA digunakan untuk melakukan validasi konstruk (Farmawati \& Hidayati, 2018; Salsabila dkk., 2019). Hasil analisis CFA untuk menguji alat ukur perilaku inovatif ditunjukkan pada gambar 2.

Tabel 3

Rekapitulasi Hasil Content Validity Index Kueasioner Innovative Behavior

\begin{tabular}{lcccc}
\hline Aitem & Clarity & Relevancy & Importancy & Hasil \\
\hline IB1 & 1.00 & 1.00 & 1.00 & Dipakai \\
IB2 & 1.00 & 1.00 & 1.00 & Dipakai \\
IB3 & 1.00 & 1.00 & 1.00 & Dipakai \\
IB4 & 1.00 & 1.00 & 1.00 & Dipakai \\
IB5 & 1.00 & 1.00 & 1.00 & Dipakai \\
IB6 & 1.00 & 1.00 & 1.00 & Dipakai \\
IB7 & 1.00 & 1.00 & 1.00 & Dipakai \\
IB8 & 1.00 & 1.00 & 1.00 & Dipakai \\
IB9 & 1.00 & 1.00 & 1.00 & Dipakai \\
IB10 & 1.00 & 1.00 & 1.00 & Dipakai \\
\hline
\end{tabular}

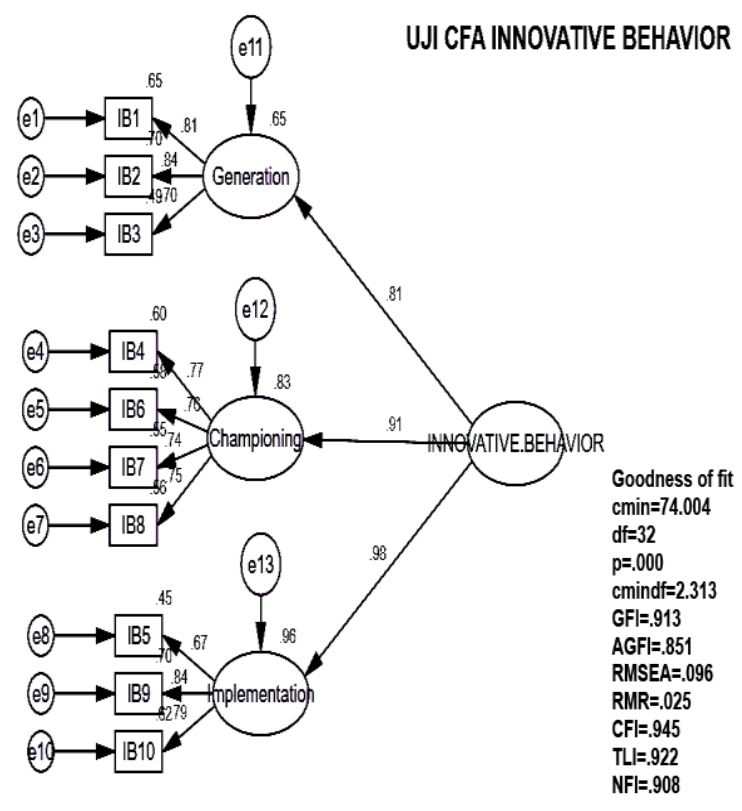

Gambar 2. Hasil uji model perilaku inovasi
Setelah diperoleh model fit, langkah selanjutnya adalah menguji signifikansi masing-masing item pada setiap dimensi. Jika diperoleh item yang signifikan maka dapat diteruskan pada analisis berikutnya. Namun, jika diperoleh item yang tidak signifikan maka item tersebut dapat dieliminasi dari model. Sebuah item dikatakan signifikan ketika memiliki nilai p-value lebih kecil dari .05 (Ghozali \& Fuad, 2008). Hasil analisis menunjukkan bahwa keseluruhan item dinyatakan signifikan.

Selanjutnya, dilakukan uji convergent validity. Sebuah item dikatakan memiliki convergent validity yang baik jika nilai loading factor diatas .50 (Azwar, 2010; Ghozali \& Fuad, 2008; Hair dkk., 2010). Jika ditemukan item dengan loading factor yang kecil (kurang dari .50) akan dilakukan penghapusan agar hasil pengujian goodness of fit menjadi lebih baik. Setelah dilakukan penghapusan, dilakukan analisis faktor ulang. Pada penelitian ini skala perilaku inovatif menggunakan hasil pengembangan dari De Jong dan Hartog (2008) yang diadaptasi ke dalam bahasa Indonesia, dalam penelitian tersebut ditemukan bahwa variabel ini termasuk ke dalam multidimensional.

Tabel 4

Hasil Analisis Item Skala Perilaku Inovatif Standardized Regression Weights

\begin{tabular}{|c|c|c|c|}
\hline & & & Estimate \\
\hline Generation & $\leftarrow$ & $\begin{array}{l}\text { Innovative. } \\
\text { Behavior }\end{array}$ & .807 \\
\hline Championing & $\leftarrow$ & $\begin{array}{l}\text { Innovative. } \\
\text { Behavior }\end{array}$ & .912 \\
\hline Implementation & $\leftarrow$ & $\begin{array}{l}\text { Innovative. } \\
\text { Behavior }\end{array}$ & .978 \\
\hline IB3 & $\leftarrow$ & Generation & .703 \\
\hline IB2 & $\leftarrow$ & Generation & .839 \\
\hline IB 1 & $\leftarrow$ & Generation & .808 \\
\hline IB8 & $\leftarrow$ & Championing & .751 \\
\hline IB7 & $\leftarrow$ & Championing & .742 \\
\hline IB6 & $\leftarrow$ & Championing & .760 \\
\hline IB4 & $\leftarrow$ & Championing & .774 \\
\hline IB 10 & $\leftarrow$ & Implementation & .790 \\
\hline IB9 & $\leftarrow$ & Implementation & .839 \\
\hline IB5 & $\leftarrow$ & Implementation & .674 \\
\hline
\end{tabular}


Perilaku inovatif terdiri dari 10 item yang menggunakan tiga dimensi yaitu dimensi idea generation terdiri dari 3 item, dimensi idea championing terdiri dari 4 item dan dimensi idea implementation terdiri dari 3 item.

Hasil nilai loading factor pada analisis CFA ditunjukkan pada tabel 4. Hasil tersebut menunjukkan bahwa keseluruhan item memiliki nilai loading factor melebihi .5. Dengan kata lain, item-item tersebut mampu mengukur perilaku inovatif karyawan hotel. Secara rinci, item dari idea generation memiliki nilai loading factor berkisar antara .703 - .839. Sementara itu, item dari idea championing memiliki loading factor berkisar antara .742 - .774. Sedangkan item dari idea implementation memiliki nilai loading factor berkisar antara $.674-.839$.

Selain itu, pada variabel laten ketiga dimensi pengukur perilaku inovatif yang terdiri dari idea generation, idea championing, dan idea implementation juga menunjukkan perolehan nilai loading factor yang tinggi yaitu berkisar antara .807 .978. Nilai tersebut bermakna bahwa item maupun dimensi memiliki validitas yang tinggi. Dengan demikian, temuan ini mengindikasikan bahwa ketiga dimensi yang terdiri dari idea generation, idea championing, dan idea implementation mampu menjelaskan perilaku inovatif karyawan hotel.

\section{Simpulan}

Alat ukur perilaku inovatif yang diadaptasi ke dalam bahasa Indonesia dan diberikan kepada karyawan sales marketing di perhotelan menunjukkan sifat yang multidimensi dalam mengukur perilaku inovatif di tempat kerja dengan tiga dimensi yaitu dimensi idea generation, idea championing dan idea implementation. Proses adaptasi alat ukur sangat penting agar mendapatkan item-item yang cukup valid sebelum diberikan kepada subjek penelitian. Hasil validitas diperoleh dari proses adaptasi oleh para ahli bidang bahasa dan bidang kerja di perhotelan sesuai dengan subjek penelitian. Hal ini penting dilakukan agar mendapatkan alat ukur yang memiliki kesamaan makna dari bahasa asli alat ukur.

Pengujian validitas dengan menggunakan confirmatory factor analysis (CFA) menunjukkan bahwa skala ini memiliki nilai validitas dan reliabilitas item yang tergolong tinggi. Hasil perhitungan menunjukkan model konstruk skala perilaku inovatif dinyatakan fit. Hasil perhitungan item menunjukkan skala perilaku inovatif memiliki perubahan yang signifikan dengan nilai estimasi loading factor yang tinggi yaitu antara .674 - .978. Hasil penelitian ini menunjukkan bahwa semua item pada skala perilaku inovatif dapat dipakai untuk mengukur perilaku inovatif karyawan sales marketing di perhotelan.

\section{Daftar Pustaka}

Akram, T., Lei, S., Haider, M. J., \& Hussain, S. T. (2020). The impact of organizational justice on employee innovative work behavior: Mediating role of knowledge sharing. Journal of Innovation \& Knowledge, 5(2), 117129.

https://doi.org/https://doi.org/10.1016/j .jik.2019.10.001

Anshori, Y. (2010). Tourism board: Strategi promosi pariwisata daerah. ITS Press.

Azwar, S. (2010). Metode penelitian. Pustaka Pelajar.

Badan Pusat Statistik. (2015). Statistik hotel dan akomodasi lainnya di Indonesia 2015. Jakarta.

Basu, R., \& Green, S. R. (1997). Leadermember exchange and transformational leadership: An empirical examination of innovative behaviors in leader-member dyads. Journal of Applied Social Psychology, 27 , 477-499. https://doi.org/10.1111/j.15591816.1997.tb00643.x 
Bunce, D., \& West, M. A. (1995). Self perceptions and perceptions of group climate as predictors of individual innovation at work. Applied Psychology: An International Review, 44(3), 199-215. https://doi.org/10.1111/j.14640597.1995.tb01076.x

Byrd, J., \& Brown, P. L. (2003). The innovation equation: Building creativity and risk-taking in your organization. Jossey-Bass/Pfeiffer.

Caloghirou, Y., Kastelli, I., \& Tsakanikas, A. (2004). Internal capabilities and external knowledge sources: Complements or substitutes for innovative performance? Technovation, 24(1), 29-39.

Christoph, S., Werr, A., \& Reihlen, M. (2018). Professions and professional service firms. In Professions and Professional Service Firms (pp. 110133). Routledge.

De Jong, J. P., \& Den Hartog, D. N. (2007). How leaders influence employees' innovative behaviour. European Journal of Innovation Management, 10(1), 41-64. https://hdl.handle.net/11245/1.529560

De Jong, J. P., \& Hartog, D. D. (2008). Innovative work behavior: Measurement and validation. EIM Business and Policy Research.

Deeb, G. (2015). Big companies that embrace intrapreneurship will thrive. https://www.entrepreneur.com/article/2 43884

Farmawati, C., \& Hidayati, N. (2019). Penyusunan dan pengembangan alat ukur islamic personality scale (IPS). JPIB: Jurnal Psikologi Islam dan Budaya, 2(1), 19-30. http://doi.org/10.15575/jpib.v2i1.4318

Ghozali, I., \& Fuad. (2008). Structural equation modeling: Teori, konsep dan aplikasi dengan program lisrel 8.0. Badan Penerbit Universitas Diponegoro.

Hair, J. F., Black, W. C., Babin, B. J., \&
Anderson, R. E. (2010). Multivariate data analysis: A global perspective $\left(7^{\text {th }}\right)$. Pearson Prentice Hall.

Jung, H. S., \& Yoon, H. H. (2018). Improving frontline service employees' innovative behavior using conflict management in the hospitality industry: The mediating role of engagement. Tourism Management, 69 , 498-507.

https://doi.org/https://doi.org/10.1016/j .tourman.2018.06.035

Kagermann, H. (2015). Change through digitization: Value creation in the age of industry 4.0. Dalam H. Albach, H. Meffert, A. Pinkwart, \& R. Reichwald (Eds.), Management of permanent change (pp. 23-45). Springer Gabler.

Kör, B., Wakkee, I., \& van der Sijde, P. (2020). How to promote managers' innovative behavior at work: Individual factors and perceptions. Technovation, 102127. https://doi.org/https://doi.org/10.1016/j .technovation.2020.102127

Krejcie, R. V., \& Morgan, D. W. (1970). Determining sample size for research activities. Educational and Psychological Measurement, 30(3), 607-610.

https://doi.org/10.1177/001316447003 000308

Kwon, K., \& Kim, T. (2020). An integrative literature review of employee engagement and innovative behavior: Revisiting the JD-R model. Human Resource Management Review, $30(2)$.

https://doi.org/https://doi.org/10.1016/j .hrmr.2019.100704

Luu, T. T. (2019). Can diversity climate shape service innovative behavior in Vietnamese and Brazilian tour companies? The role of work passion. Tourism Management, 72, 326-339. https://doi.org/https://doi.org/10.1016/j .tourman.2018.12.011

Mahfud, T., Jati, B. K. \&, \& Mulyani, Y. (2017). Soft skill competency map for 
the apprenticeship programme in the Indonesian Balikpapan hospitality industry. Journal of Technical Education and Training, 9.

Mahfud, T., Pardjono, \& Lastariwati, B. (2019). Chef's competency as a key element in food tourism success: A literature review. Geojournal of Tourism and Geosites, 26(3), 10571071.

https://doi.org/https://doi.org/10.30892 /gtg.26329-417

Martin, I., Ramos, M., \& Herrero, L. A. R. (2018). Intrapreneurship in business innovation: The importance of intellectual capital protectioncapitalize on the commitment of its human capital. Dalam A. C. Moreira, J. G. L. Dantas, \& F. M. Valente (Eds.), Nascent Entrepreneurship and Successful New Venture Creation (pp. 153-174). IGI Global.

Metcalfe, J. S., \& Miles, I. (2012). Innovation systems in the service economy: Measurement and case study analysis. Springer Science \& Business Media.

Polit, D. F., \& Beck, C. T. (2006). The content validity index: Are you know whats being reported? Research in Nursing \& Health, 29, 489-497.

Rigtering, J. C., Weitzel, G. U., \& Muehlfeld, K. K. (2019). Increasing quantity without compromising quality: How managerial framing affects intrapreneurship. Journal of Business Venturing, 34(2), 224-241. https://doi.org/https://doi.org/10.1016/j .jbusvent.2018.11.002

Rosyiana, I. (2019). Innovative behavior at work: Tinjauan psikologi \& implementasi di organisasi. Deepublish.

Salsabila, D. F., Rofifah, R., Natanael, Y., \& Ramdani, Z. (2019). Uji validitas konstruk indonesian-psychological measurement of islamic religiousness (I-PMIR). JPIB: Jurnal Psikologi Islam dan Budaya, 2(2), 77-86. http://doi.org/10.15575/jpib.v2i2.5494

Sperber, A. D. (2004). Translation and validation of study instruments for cross-cultural research. Gastroenterology, 126, 124-128. https://doi.org/doi:10.1053/j.gastro.200 3.10 .016

Suhariadi, F. (2002). Proses pembentukan perilaku produktif pada budaya kerja organisasi. Proceeding Temu Ilmiah I APIO.

Tewal, B. (2010). Pengaruh strategi bersaing dan inovasi terhadap kinerja perusahaan perhotelan di Sulawesi Utara. Jurnal Aplikasi Manajemen, 8(2), 464-470.

Wu, C., de Jong, J. P. J., Raasch, C., \& Poldervaart, S. (2020). Work processrelated lead userness as an antecedent of innovative behavior and user innovation in organizations. Research Policy, $\quad 49(6), \quad 103986$. https://doi.org/https://doi.org/10.1016/j .respol.2020.103986

Wu, M., Siswanto, I., \& Mahfud, T. (2018). The role of cognitive and affective behavior in predicting the creative thinking of university students. International Journal of Innovation, Creativity and Change, 4(2), 90-103.

Yong, L. B., \& Elsye, S. (2016). Pengaruh marketing capability terhadap financial performance dengan innovation capability sebagai variabel intervening pada industri perhotelan di Surabaya. Business Accounting Review, 4(1), 445-456.

Zhou, J., \& George, J. M. (2001). When job dissatisfaction leads to creativity: Encouraging the expression of voice. Academy of Management Journal, 44(4), 682-696. https://doi.org/10.2307/3069410 
Psympathic, Jurnal Ilmiah Psikologi Juni 2020, Vol. 7, No. 1, Hal. : 39-48 